100

http://dx.doi.org/10.1590/0100-2945-450/13

\title{
PRODUÇÃO DE AMOREIRA-PRETA NO BRASIL ${ }^{1}$
}

\author{
LUÍS EDUARDO CORREAA ANTUNES ${ }^{2}$, IVAN DOS SANTOS PEREIRA ${ }^{3}$, \\ LUCIANO PICOLOTTO ${ }^{3}$, GERSON KLEINICK VIGNOLO ${ }^{3}$, MICHEL ALDRIGHI GONÇALVES
}

RESUMO - O cultivo da amoreira-preta vem crescendo nos últimos anos. Este aumento da demanda é atribuído a vários fatores, de econômicos a sociais, que também ocorre devido às suas qualidades fitoquímicas, que podem trazer benefícios à saúde, a partir da busca por uma alimentação mais saudável. Além disso, trata-se de uma cultura com características, que a tornam uma opção viável para a pequena propriedade. O objetivo do presente artigo foi realizar uma atualização de literatura sobre a cultura da amoreira-preta, buscando verificar as principais tecnologias de manejo, assim como as carências do sistema de produção e o cenário para os próximos anos no Brasil.

Termos para indexação: Rubus, manejo, cultivares, nutrição e propriedades nutracêuticas.

\section{BLACKBERRY PRODUCTION IN BRAZIL}

\begin{abstract}
The cultivation of blackberry has grown so intense in recent years. A fact attributed to the increased demand is attributed to several factors, from the economic to the social, which also occurs due to their phytochemical qualities that can bring health benefits, beginning for looking a healthier diet. Moreover, it is a culture whose features, making it a viable option for small properties. The objective of this study was to perform an update article of literature on the culture of blackberry, trying to verify the key management technologies, as well as the needs of the production system and the scenario for the next few years in Brazil. Index Terms: Rubus, cultural practices, cultivars, uptake and nutraceutical properties nutrição.
\end{abstract}

\section{INTRODUÇÃO}

Nos últimos 30 anos, a população mundial cresceu $70 \%$, mas o consumo per capita de frutas, somente $20 \%$. Apesar de haver um equilíbrio entre o consumo de frutas tropicais e temperadas, atualmente o consumo de frutas frescas temperadas tem sido um pouco maior (RETAMALES, 2011). O aumento da área cultivada e a produção de frutas de clima temperado têm crescido no Brasil. Isso ocorreu principalmente devido à modernização e à melhor gestão da propriedade rural e de todos os fatores de produção, à adoção de tecnologias de baixo impacto ambiental, visando à qualidade, segurança do produto e preservação do meio ambiente e, deste modo, atendendo às exigências do mercado consumidor brasileiro e transpondo as rigorosas barreiras fitossanitárias impostas pelos países importadores (FACHINELLO et al., 2011).

Devido ao baixo custo de implantação, manutenção do pomar, e principalmente a necessidade reduzida de agrotóxicos, o cultivo de amora-preta (Rubus sp.) é, também, uma boa opção para o cultivo agroecológico (ANTUNES et al., 2010), sendo que a cultura se apresenta como importante opção de diversificação na agricultura familiar.

A amoreira-preta é um arbusto cujas espécies pertencem ao gênero Rubus. Embora haja espécies nativas do Brasil, as cultivares utilizadas atualmente no País são oriundas de cruzamentos envolvendo material genético nativo dos Estados Unidos. É considerada uma cultura de retorno rápido, tendo em vista que entra em produção já no segundo ano de cultivo. Outra característica interessante é a possibilidade de comercialização, pois trata-se de uma fruta que possibilita a elaboração de uma grande variedade de produtos, tais como, iogurtes, geleias, doces e sucos, além de ser comercializada in natura e também na forma de polpa.

$\mathrm{O}$ recente interesse pelo consumo da amorapreta, associado à adaptação da cultura a algumas regiões do País, tem proporcionado a ampliação da área de produção, principalmente no Estado do Rio Grande do Sul (SCHAKER; ANTONIOLLI, 2009) e em algumas regiões dos Estados de São Paulo e Minas Gerais, com microclima favorável à cultura

'(Trabalho 450-13). Recebido em: 20-09-2013. Aceito para publicação em: 15-12-2013. Palestra II Simpósio Internacional de Fruticultura- Frutas Exóticas, 21 a 25 de outubro de 2013. Jaboticabal-SP.

${ }^{2}$ Eng. Agrôn., Dr., Pesquisador da Embrapa Clima Temperado, Pelotas-RS, Bolsista CNPq. E-mail: luis.antunes@embrapa.br ${ }^{3}$ Eng. Agrôn., Dr., Bolsista PNPD/Capes da Embrapa Clima Temperado Pelotas-RS, Bolsista Capes PNPD. E-mail: ivanspereira@ gmail.com, picolotto@gmail.com 
(SEGANTINI et al., 2011).Tal situação propicia a essas regiões enormes possibilidades de mercado para a produção de frutas frescas e industrializadas. De acordo com ILHA (2012), fatores como aumento do poder aquisitivo da população, mudanças no hábito alimentar, busca da diversificação das propriedades rurais, pesquisa agropecuária, assistência técnica e extensão rural contribuíram para o cenário atual.

\section{Aspectos produtivos e econômicos da amora-preta}

Por ser uma cultura em expansão, há pouca informação atualizada a respeito da produção e da área plantada. Segundo Strik et al. (2007), a produção mundial de amora-preta, em 2005, foi de 20.035 ha, sendo 7.692 ha cultivados na Europa, 7.159 ha na América do Norte, 1.640 ha na Central América, 1.597 ha na América do Sul, 297 ha na Oceania e 100 ha na África. A produção mundial, em 2005, foi de 140.292 toneladas, tendo como principais países produtores os Estados Unidos (31.840 t), o México (26.985 t), a China (26.350 t), a Sérvia (25.000 t) e a Hungria (12.000 t).

No ano de 2005, segundo Strik et al. (2007), a área plantada com amora-preta no Brasil era de 250 ha, sendo que, nos últimos anos, a mesma aumentou cerca de $100 \%$, chegando a aproximadamente 500 ha. Os principais Estados produtores estão localizados nas regiões Sul e Sudeste, sendo eles, Rio Grande do Sul, Santa Catarina, Paraná, Minas Gerais, São Paulo e Espírito Santo (Tabela 1).

Atualmente, estima-se que, no Rio Grande do Sul, sejam produzidas 2.209,5 toneladas em 239,2 ha, destacando-se os municípios de Campestre da Serra e Vacaria, com áreas de 80 e 78 ha, respetivamente. Em Santa Catarina, o cultivo da amora-preta ocupa uma área de aproximadamente 10 ha. No Paraná, estima uma produção de 173,4 toneladas, em uma área de 22,1 ha. Em São Paulo, os últimos levantamentos sobre o cultivo de amora-preta, na safra de 2007/2008, indicam uma área de 213,5 ha. Já em Minas Gerais, estima-se que foram produzidas nos últimos anos cerca de 320 toneladas em 40 hectares. No Espírito Santo, as áreas de produção são restritas a regiões de altitude elevada, contabilizando aproximadamente 3,0 ha (Tabela 1).

O preço médio pago ao produtor varia em função da época de produção e da forma de comercialização (in natura ou indústria). A comercialização na forma in natura ainda é pequena e praticada geralmente em feiras dos principais centros consumidores da região Sul e Sudeste do País. Por outro lado, a industrialização é mais comum devido ao baixo período de conservação da fruta.
Informações sobre comercialização desta cultura, no Brasil, são escassas.

De acordo com dados obtidos junto à Emater/ RS-ASCAR, de Vacaria-RS, na safra de 2010/2011, o preço da amora-preta, pago ao produtor, para o fruto destinado à indústria de processamento, foi de $\mathrm{R} \$$ 1,20 a $\mathrm{R} \$ 1,50$ por quilo, enquanto para o mercado in natura, foi de R\$2,50 a R \$ 3,00 por quilo. Preços que podem ser considerados baixos, tendo em vista a exigência de mão de obra da cultura. Porém, isso ocorre porque a produção está concentrada em uma determinada época do ano.

Segundo dados de preço médio pago pelo consumidor, apresentados pela CEASA-RS, nas safras de 2011/2012 e 2012/2013, os menores valores da amora-preta são observados a partir do início do mês de novembro até o final de dezembro (Figura 1). Sendo esse justamente o período no qual concentra o maior percentual da produção das principais cultivares (Figura 1). Em contraste, os períodos anterior e posterior são de preços bastante elevados, principalmente nos meses de agosto, setembro e outubro, em que o preço pago pelo consumidor pode chegar a valores superiores a $\mathrm{R} \$ 35,00 \mathrm{~kg}^{-1}$. Com base neste exercício, fica claro que a produção fora de época, especialmente antes da safra, é uma grande oportunidade para os produtores de amora-preta.

Além disso, o período de produção de amora-preta no Brasil leva a perspectiva de aumento na procura para exportação destas frutas, visando a atender à entressafra do Hemisfério Norte (FACHINELLO et al., 2011).

\section{Cultivares e sistemas de produção}

No Brasil, o programa de melhoramento da amoreira-preta foi iniciado na década de 70 , com a introdução de uma pequena coleção de cultivares, da qual faziam parte 'Brazos', 'Cherokee' e 'Comanche', além de um clone do Uruguai de identidade desconhecida. Posteriormente, foram trazidas sementes de cruzamentos realizados na Universidade de Arkansas, Estados Unidos, de onde se originaram seedlings, das quais foram obtidas as primeiras seleções. As cultivares lançadas pelo programa de melhoramento da Embrapa Clima Temperado são as seguintes: 'Ébano', em 1981; 'Negrita', em 1983; 'Tupy' e 'Guarani', em 1988; 'Caingangue', em 1992, e 'Xavante', em 2004 (RASEIRA; FRANZON, 2012).

Atualmente, Tupy é a cultivar mais importante no Brasil e considerada, também, a mais importante em todo o mundo (VOLK et al., 2013), devido a sua elevada produtividade e à qualidade dos frutos (Figura 2). No pico de produção, com manejo 
adequado, pode atingir produtividades superiores a $25 \mathrm{tha}^{-1}$, porém, em média, são observadas produções de 10 a $16 \mathrm{t} \mathrm{ha}^{-1}$ (Tabela 2). Além disso, apresenta frutos com boa aceitação no mercado in natura, devido ao seu tamanho, uniformidade, firmeza, coloração intensa e sabor. Outra característica que torna essa cultivar importante mundialmente é sua capacidade de adaptação a diferentes condições edafoclimáticas e de manejo.

Podem-se destacar, também, as cultivares sem espinho, Xavante e Ébano, que proporcionam ao produtor maior facilidade na execução de algumas práticas culturais, tais como a poda, a condução e a colheita. Entretanto, essas cultivares podem apresentar problemas relacionados à conservação e à qualidade do fruto. Pesquisas realizadas com a cultivar Xavante indicam menor firmeza dos frutos, característica que dificulta o transporte e a armazenagem, além do sabor amargo, fazendo com que seja indicada para o processamento e sendo menos atrativa ao consumo in natura (PEREIRA, 2008).

As demais cultivares, como Caingangue, Guarani e Negrita, apresentam importância intermediária, possuindo características similares à Tupy, porém são menos produtivas e/ou seus frutos são de menor qualidade. Desta forma, o conjunto destas cultivares, incluindo as sem espinho, representa em torno de $10 \%$ da área cultivada no Brasil. Em Vacaria-RS, há empresas que cultivam cultivares sem espinho, como Chester Thornfree e Lochness.

Outro aspecto importante na escolha da cultivar e que está relacionado com o preço pago ao produtor pela fruta, diz respeito à época de colheita. Para essa característica, observa-se que a maioria das cultivares tem seu período de colheita concentrado em uma mesma época, compreendida entre os meses de novembro e janeiro (Tabela 3 ).

Algumas das cultivares plantadas no Brasil necessitam de tutor para suportar o peso das hastes e da produção. A condução das plantas também é importante para evitar o contato dos frutos com o solo. Na escolha do sistema de condução, deve-se levar em consideração o hábito de crescimento de cada cultivar. Nas cultivares de hábito prostrado, geralmente, utiliza-se a condução na forma de espaldeira simples ou dupla, sistema que proporciona incrementos da produção acima de $50 \%$.

Visando à diminuição do custo com a implantação do sistema de condução, pode-se realizar o cultivo sem tutoramento; no entanto, neste sistema, ocorre uma redução da produção em função da necessidade de encurtamento das hastes comparado ao sistema de tutoramento em espaldeira. As formas dos sistemas de suporte adotado variam com o tipo de material disponível na propriedade. Segundo Pagot et al. (2007), o sistema de condução mais utilizado para a amoreira-preta é em forma de ' $\mathrm{T}$ ', com travessas fixadas a uma altura de 1,0 a $1,20 \mathrm{~m}$ do solo, por onde passam 2 arames paralelos, com 40 a $50 \mathrm{~cm}$ de distância um do outro. Quando as brotações das plantas, emitidas junto ao solo, ultrapassarem os arames, devem ser amarradas.

De acordo com Pagot et al. (2007), um grande número de pragas e doenças pode atacar a cultura da amoreira-preta. As principais doenças e pragas no Sul do Brasil são: Botrytis ou mofocinzento (Botrytis cinerea), antracnose do fruto (Colletotrichum gloeosporioides), cancro dos ramos (Botryosphaeria dothidea), ferrugem-alaranjada (Gimnoconia nitens), a ferrugem dos ramos e folhas (Kuehneola uredinis) e a ferrugem da amoreirapreta (Phragmidium violaceum), galha-da-coroa (causada pela bactéria do solo Agrobacterium Tumefasciens), broca-da-amora (Eulechriops rubi Hespenheide, 2005) e mosca-das-frutas (Anastrepha spp). No caso das doenças, as estratégias de manejo em outros países associam os métodos culturais, físicos, biológicos e a proteção química das plantas com fungicidas. As recomendações de controle das principais pragas e doenças enfatizam o uso de mudas sadias e a profilaxia, que visam à redução das fontes de inóculo e de sua evolução dentro da área de produção. A estas práticas, são acrescentadas a adubação equilibrada, a condução aberta das plantas, a manutenção da cobertura verde baixa e cobertura plástica dos cultivos, e o controle químico com produtos cúpricos, enxofre e calda sulfocálcica.

\section{Características do solo recomendadas para amoreira-preta}

Em geral a amoreira-preta tolera uma ampla gama de solos, porém desenvolve-se melhor em solos arenosos com bom teor de matéria orgânica (GRANDALL, 1995; GAZDA; KOCHMANSKABEDNARZ, 2010). O sistema radicular não tolera solos encharcados, devendo-se evitar solos pesados, ou áreas com propensão a inundação, sendo o uso de camalhões uma alternativa importante para locais periodicamente molhados (FERNANDEZ; BALLINGTON, 1999).

Em relação ao $\mathrm{pH}$, há uma série de indicações e muitas divergências entre as recomendações encontradas na literatura. Segundo Ilha (2012), antes da instalação do pomar, no mínimo três meses antes, aplica-se calcário, preferentemente dolomítico, para elevar o pH a 5,5. No entanto, Fernandez e Ballington 
(1999) sugerem que os solos mais satisfatórios são os que apresentam pH de 6,0 a 6,5. Por sua vez, Grandall (1995) indica a faixa entre $\mathrm{pH}$ 5,5 e 6,5 como a melhor para a amoreira-preta.

Já para Dickerson (2000), as amoreiras-pretas necessitam de solos com $\mathrm{pH}$ entre 6,5 e 7,5. O mesmo autor cita ainda que, em solos com $\mathrm{pH}$ maior que 7,5, o único problema para o cultivo seria que as plantas podem desenvolver cloroses devido à deficiência de ferro.

No que diz respeito ao teor de matéria orgânica do solo (MOS), diferentes autores sugerem faixas semelhantes. Fernandez et al. (1999) indicam o teor de MOS entre 2 e $4 \%$ como sendo satisfatório. Para Grandall (1995), esse teor seria de 3 \%. Já Freire (2007) sugere que 4,5\% seria uma taxa satisfatória e que, inclusive, não seria necessária a adubação nitrogenada.

\section{Nutrição e adubação}

A nutrição mineral é um dos principais aspectos do cultivo da amoreira-preta que ainda necessita ser aperfeiçoado (STRIK; FINN, 2012). No Brasil, existem poucas informações sobre a prática de adubação, e a resposta da aplicação de nutrientes para essa cultura, sendo essa, realizada a partir da interpretação de resultados de pesquisa obtidos em outras regiões do mundo. Atualmente, a recomendação de adubação é baseada apenas em análise de solo, sendo as doses de nitrogênio, fósforo e potássio, recomendadas em relação aos teores de matéria orgânica, fósforo e potássio no solo, respectivamente (CQFS-SC/RS, 2004; FREIRE, 2007; ILHA, 2012).

Em relação à análise foliar, as tabelas que indicam o estado nutricional da planta, foram elaboradas com teores foliares da cultura da framboesa, também espécie pertencente ao gênero Rubus. Panorama preocupante, já que é de consenso que a análise foliar, em conjunto com a de solo, é de fundamental importância para uma correta interpretação do estado nutricional e recomendação da adubação.

Ao contrário do que ocorre no Brasil, nos principais países produtores de amora-preta no mundo, as recomendações de adubação levam em conta grupos de cultivares. Em geral, as cultivares são agrupadas de acordo com o seu hábito de crescimento, podendo ser rasteira, eretas ou semieretas, havendo exigências e recomendações nutricionais específicas para cada grupo (HART et al., 2006; STRIK, 2008; STRIK; FINN, 2012).

A necessidade dos produtores e a carência de informações sobre a nutrição da amoreira-preta no
Brasil estimularam o início dos trabalhos com esse tema na Embrapa Clima Temperado, em Pelotas-RS. Os experimentos voltados à adubação de manutenção estão sendo conduzidos há cerca de quatro anos, e os dados preliminares indicam a necessidade de refinamento das recomendações atuais. Entre os resultados mais relevantes, está a grande diferença em termos de resposta à adubação das cultivares, ficando evidente a necessidade de levar em conta as diferenças entre os genótipos. Observou-se, ainda, que as recomendações de adubação potássica estão abaixo do necessário, principalmente na cultivar Tupy (dados não publicados).

Para amoreira-preta, o elemento utilizado em maior quantidade é o nitrogênio (N) (STRIK, 2008), sendo o principal fator de manejo que influencia sobre o vigor, o tamanho e o número de hastes, assim como sobre o tamanho e a qualidade dos frutos (PAPP et al., 1984; GALLETTA; HILMELRICK, 1990; GRANDALL, 1995). A deficiência de N é caracterizada pela presença de entrenós curtos, folhas pequenas, cloróticas, que caem prematuramente, hastes finas, curtas e em número reduzido, além de frutos pequenos. Na planta, o $\mathrm{N}$ é móvel, de modo que os sintomas foliares de deficiência, clorose ou amarelecimento surgem primeiro nas folhas mais velhas (Figura 3A). Se a carência for severa, pode haver a formação de regiões avermelhadas pelo acúmulo de antocianinas (Figura 3B) e até necrose (GRANDALL, 1995; FREIRE, 2007; PEREIRA et al., 2012). A toxidez de nitrogênio é rara, caracterizando-se pelo excessivo vigor das plantas, entrenós longos, folhas com coloração verde-escura, pequena produção e frutos de baixa qualidade (FREIRE, 2007).

O potássio $(\mathrm{K})$ é essencial e usado em grandes quantidades pela amoreira-preta (GRANDALL, 1995; FREIRE, 2007; PEREIRA et al., 2012). Em situações de alta produtividade, em que o $\mathrm{N}$ não é limitante, o K pode induzir o crescimento, aumentar a produtividade, além de influenciar sobre firmeza dos frutos. Já a deficiência de K pode causar clorose e necrose marginal das folhas, além de as mesmas apresentarem-se recurvadas com coloração marrom (Figura 3D).

Embora seja um elemento essencial, adições de fósforo (P), até mesmo para solos com baixos níveis do elemento, raramente resultam em aumentos de rendimento para a amoreira-preta (FREIRE, 2007). No entanto, o P contribui para o crescimento do sistema radicular e interage com outros elementos, podendo proporcionar o aumento da produção e a qualidade dos frutos (GRANDALL, 1995; PEREIRA et al., 2012). Em experimentos de nutrição realizados 
na Embrapa Clima Temperado-RS, os sintomas da deficiência de P observados foram inicialmente em folhas mais velhas, que se tornam verde-escuras com bordas arroxeadas (Figura 3C), podendo haver, ainda, queda prematura das folhas.

Entre os micronutrientes, a deficiência de boro (B) pode causar atraso na brotação e morte de gemas, principalmente na porção superior das hastes. Deficiências de zinco $(\mathrm{Zn})$ provocam amarelecimento ou morte da área internerval de folhas mais velhas, entrenós curtos e crescimento terminal em forma de roseta. Já a deficiência de manganês ( $\mathrm{Mn}$ ) não é comum, porém alguns sintomas são folhas mais velhas com coloração amarelada e superiores normais (GRANDALL, 1995).

\section{Produção fora de época}

A produção de amora-preta no Brasil estendese de outubro a fevereiro, não havendo oferta interna do produto fora deste intervalo (ANTUNES et al., 2006a). Entretanto, a produção fora de época pode ser uma opção bastante interessante economicamente, uma vez que a remuneração pode ser até 700\% superior ao período normal da safra.

A antecipação ou o retardamento da produção é possível pela modificação dos fatores ambientais e/ ou de técnicas de manejo para cultura. Entretanto, é conveniente que a cultivar tenha baixo requerimento em frio e calor para brotar, assim como um período curto para a formação de flores e frutos.

O controle de fatores ambientais, como temperatura e umidade, em geral, apresentam custo elevado; no entanto, através do cultivo protegido, é uma alternativa interessante. Uma opção viável é a utilização de túneis, a qual incrementa a produção, preserva a qualidade dos frutos e melhora a sanidade das plantas (THOMPSON et al., 2009; STRIK; FINN, 2012; HANSON et al., 2011). Mas, são necessárias adequações em relação à necessidade de água, nutrientes e do manejo da cultura para esse sistema de produção (STRIK; FINN, 2012).

Em relação ao manejo, as técnicas mais eficazes para a alteração do período de produção são a poda extemporânea e a aplicação de reguladores de crescimento. A poda da amoreira-preta é realizada em dois momentos: uma no verão, momento em que se eliminam as hastes que produziram e encurtam-se as novas hastes emergidas do solo, e outra no inverno, reduzindo-se as hastes laterais (GONÇALVES et al., 2011; CAMPAGNOLO; PIO, 2012).

Entretanto, com o objetivo de produzir fora da época convencional, pode-se realizar a poda extemporânea de inverno e verão de forma escalonada. A poda extemporânea de verão, realizada após a colheita, elimina os ramos senescentes que produziram e estimula a brotação de novos, cujas gemas podem diferenciar-se e florescer, antecipando a produção (ANTUNES et al., 2006a). No inverno, quando a poda extemporânea é realizada no início ou meados de julho, proporciona resultados satisfatórios em termos de produção, porém sem alterar de forma importante a época de colheita; por outro lado, quando é efetuada de forma mais tardia (final de julho e início de agosto), pode expor as hastes a condições climáticas adversas, como geadas tardias, que prejudicam o desempenho produtivo (CAMPAGNOLO; PIO, 2012). Em geral, a poda fora de época gera um volume produzido abaixo do observado em uma safra onde a poda foi realizada na época convencional, porém, dependendo da alteração do período de colheita, o preço recebido pelo produtor pode compensar.

Outra possibilidade para a produção fora de época é o uso de reguladores de crescimento (Figura 4). Essa é uma técnica empregada em larga escala pelos produtores de amora-preta no México, que a chamam de produção forçada. Consiste na aplicação de reguladores de crescimento, como o thidiazuron (TDZ) (N-fenil-N-1,2,3-tidiazol-5ilurea), a cianamida hidrogenada $(\mathrm{CH})\left(\mathrm{H}_{2} \mathrm{CN}_{2}\right)$, o ácido giberélico $\left(\mathrm{AG}_{3}\right)$, associados à supressão da irrigação e da desfolha.

$\mathrm{O}$ thidiazuron é uma fenilureia que favorece a atividade citocínica que induz a saída de dormência e reduz a necessidade de frio da cultura para brotar (CAMPOY et al., 2011; THERON et al., 2011). Doses entre 50 e $250 \mathrm{mg} \mathrm{L}^{-1}$ de TDZ, associadas ou não ao ácido giberélico e/ou à cianamida hidrogenada, têm promovido a antecipação da brotação, floração e maturação, assim como o incremento da produção em diversas cultivares de amoreira-preta no México (GALINDO-REYES et al., 2004). A cianamida hidrogenada e o ácido giberélico, assim como o thidiazuron, têm-se mostrado efetivos para a antecipação e uniformização da brotação e da colheita (CALDERÓN; RODRÍGUEZ, 1992; GEORGE et al., 1998; SEGANTINI et al., 2011; STRIK; FINN, 2012). Segantini et al. (2011) indicam a aplicação de cianamida hidrogenada a 4,5\%, na região de São Manuel-SP, para a obtenção de maior uniformização e aumento da brotação e produção de frutos na cultivar Tupy. Na cultivar Comanche, a aplicação de $200 \mathrm{mg} \mathrm{L}^{-1}$ de $\mathrm{AG}_{3}$ com ureia (3\%) promoveu a brotação e o incremento da produção de frutos. 
Colheita, pós-colheita e valor nutracêutico

A amoreira-preta possui frutos extremamente frágeis, que exigem cuidados na hora da colheita, manuseio e transporte. Nesse sentido, é imprescindível que a colheita seja realizada nas primeiras horas da manhã e que os frutos sejam rapidamente retirados do campo. A exposição dos frutos ao sol, bem como a temperaturas relativamente elevadas durante o transporte, é suficiente para ocasionar a perda da coloração característica dos frutos, que adquirem tons violáceos, além de favorecer a desidratação dos mesmos pela transpiração (SCHAKER; ANTONIOLLI, 2009). Assim, é recomendado que estes frutos sejam colhidos em períodos com temperaturas mais amenas e acondicionados diretamente nas embalagens definitivas, sendo realizada, neste momento, a seleção do estádio de maturação e o descarte de frutos com defeitos ou podridões. A redução do calor de campo poderá prolongar o período de armazenamento em póscolheita (ANTUNES et al., 2003).

A utilização de baixas temperaturas constitui o fator mais importante na redução da deterioração e na maximização da vida útil da amora-preta. Associado à refrigeração, o armazenamento sob condição de atmosfera modificada ou controlada pode, quando utilizado adequadamente, resultar em benefícios adicionais (SCHAKER; ANTONIOLLI, 2009), reduzindo a atividade enzimática de degradação da parede celular da fruta, aumentando seu período de conservação (ANTUNES et al., 2006bc) e mantendo a aparência a e qualidade organoléptica por maior tempo.

A fragilidade dos frutos, associada a sua elevada taxa respiratória, acarreta em curto tempo de vida pós-colheita (GONÇALVES et al., 2012). Segundo Cia et al. (2007), frutos armazenados sob condições ambientais $\left(25^{\circ} \mathrm{C}\right.$ e $80 \%$ UR) têm sua conservação limitada a apenas um dia, devido à excessiva perda de massa e à elevada incidência de podridões. Neste sentido, vêm-se buscando técnicas que permitam a manutenção da qualidade do fruto por mais tempo. No entanto, segundo Antunes et al. (2003), frutos das cultivares Brazos e Comanche conservam-se em ambiente refrigerado $\left(2^{\circ} \mathrm{C}\right)$, podendo ser armazenados com qualidade até nove dias após a colheita. Nestas circunstâncias, ocorre a redução da acidez titulável e dos sólidos solúveis totais. A utilização de recipientes durante a armazenagem refrigerada também pode ser uma alternativa importante para aumentar o tempo de conservação da amora-preta. Segundo Joo et al. (2011), a conservação dos frutos de amora-preta com padrão de comercialização pode ser estendida de 2-3 dias $\left(0^{\circ} \mathrm{C}\right)$ sem o uso de cumbuca para 12 dias $\left(3^{\circ} \mathrm{C}\right)$ com a utilização de cumbucas fechadas de poliácido láctico ou poliestireno. Outra opção pode ser a utilização do filme $(25 \mu \mathrm{m})$ de polietileno de baixa densidade (PEBD), associado ao armazenamento refrigerado a $5^{\circ} \mathrm{C} / 90 \%$ UR. De acordo com Cia et al. (2007), essa estratégia favorece a conservação pós-colheita, sendo eficaz especialmente na perda de massa dos frutos, embora possa contribuir para o aparecimento de podridões.

Sendo a amora-preta um alimento com características nutracêuticas, os estudos de póscolheita, além de estarem direcionados ao tempo de conservação, atualmente são focados na preservação destas características. Em geral, o armazenamento refrigerado, o processamento e o local de armazenagem afetam consideravelmente as propriedades físico-químicas, os compostos bioativos e a capacidade antioxidante dos frutos de amorapreta. O armazenamento refrigerado não retém com eficiência os compostos bioativos e têm impacto negativo sobre a capacidade antioxidante, fazendose necessários, outros tratamentos juntamente com o armazenamento refrigerado para prolongar a vida útil e reter os benefícios nutracêuticos dos frutos frescos de amoras-pretas. Além disso, a secagem com ar quente e o preparo de amora-preta em calda ou geleia são formas de processamento que diminuem a concentração de compostos fenólicos totais, teores de antocianinas monoméricas totais e a capacidade antioxidante dos frutos. Por outro lado, o processo de liofilização tem pouco impacto sobre as características nutracêuticas da amora-preta, sendo a tecnologia de processamento de melhor potencial para a conservação dos compostos bioativos da amora-preta processada (WU et al., 2010).

$\mathrm{O}$ consumo regular de frutas e hortaliças está associado com o baixo risco de incidência e mortalidade por câncer e doenças cardíacas, devido à presença de compostos oriundos do metabolismo secundário, especialmente flavonoides e antocianinas, os quais apresentam grande capacidade de reagir com radicais livres que causam estresse oxidativo, portanto contribuem na prevenção destas doenças (JACQUES; ZAMBIAZI, 2011).

As frutas da amoreira-preta contêm ainda ácidos graxos essenciais que devem ser obtidos através da dieta e são importantes para regular várias funções do corpo, incluindo pressão arterial, viscosidade sanguínea, imunidade e resposta inflamatória. A amora-preta in natura é altamente nutritiva, apresentando elevado conteúdo de minerais, vitaminas $\mathrm{B}, \mathrm{A}$ e cálcio. Uma série de funções e de constituintes químicos é relatada na 
literatura internacional relacionada às qualidades da amora-preta, estando, entre eles, o ácido elágico, um composto fenólico que possui funções antioxidante, antimutagênica, anticancerígena, além de ser um potente inibidor da indução química do câncer (ANTUNES et al., 2002; VIZZOTTO et al., 2012; HIRSCH et al., 2012).

A amora-preta é um alimento em que se encontram ácidos graxos importantes para a saúde, principalmente nas cultivares 'Guarani' e 'Cherokee', que apresentam maior concentração de ácido oleico. Porém, como a amora-preta apresenta baixa concentração de gordura, não poderia ser considerada uma fonte desses ácidos graxos para a dieta humana (HIRSCH et al., 2012)

\section{Cenário Futuro}

Nos próximos anos, há uma tendência de crescimento do mercado para amora-preta em todo o mundo, sobretudo para frutos produzidos em sistemas de produção alternativos, como o agroecológico e o orgânico (ANTUNES et al., 2010; STRIK; FINN, 2012). Este crescimento do mercado tem relação com os benefícios que a amora-preta traz à saúde. Este aumento da demanda deverá ampliar sua produção, a qual deverá ocorrer também em função do baixo custo de produção, melhoria da tecnologia utilizada, alto valor agregado e mão d disponível na propriedade.

Visando a atender a esta demanda, acredita-se que será necessário intensificar as pesquisas voltadas ao incremento de produtividade, à produção fora de época, à expansão do cultivo em regiões subtropicais e tropicais, além do desenvolvimento de tecnologias que possibilitem expandir o período de armazenagem, sem alteração das características funcionais. A melhoria nas condições de armazenamento e na manutenção da qualidade da fruta deverá permitir aumento da comercialização na forma in natura, possibilitando com isso maior retorno econômico ao produtor rural.

Para o avanço da cultura, as principais pesquisas devem ser direcionadas para os aspectos de nutrição/adubação, cultivo protegido e manejo de sistemas de produção para cada cultivar ou grupos de cultivares, além do desenvolvimento de cultivares superiores às atuais, sem espinho, com alta produtividade, maior peso de frutos e resistência pós-colheita.

Visando à produção fora de época, que favorece o maior retorno econômico dos produtores e a oferta do produto por um período do ano maior, são imprescindíveis trabalhos de poda escalonada, assim como a determinação das doses e épocas de aplicação de hormônios vegetais sintéticos, associados ou não ao cultivo protegido.

No que se refere à conservação da fruta, há a necessidade de definição das condições ideais de atmosfera controlada/modificada e do tipo de recipiente de armazenagem, também levando em conta as diferenças significativas existentes entre cultivares ou grupos de cultivares.

Segundo Retamales (2011), a recente evolução na agricultura de precisão, biologia molecular, fenômica, modelagem e fisiologia de pós-colheita devem aumentar a produtividade e a qualidade nas culturas, com redução de custos para as frutas de clima temperado. As maiores demandas na produção de frutas de clima temperado são em relação à qualidade, sanidade e rastreabilidade. Os desafios são em relação aos maiores custos de energia, falta de mão de obra e agrotóxicos, pois as exigências têm sido na direção às mudanças de preferência, saúde e sustentabilidade. 
TABELA 1- Principais Estados produtores de amora-preta no Brasil.

\begin{tabular}{lc}
\hline Estado & Área de produção (ha) \\
\hline Rio Grande do Sul & \\
São Paulo $^{2}$ & 239,2 \\
Minas Gerais $^{3}$ & 213,5 \\
Paraná $^{4}$ & 40,0 \\
Santa Catarina $^{5}$ & 22,1 \\
Espírito Santo $^{6}$ & 10,0 \\
Total & 3,0 \\
\hline
\end{tabular}

Fonte: ${ }^{1}$ Antônio Conte (Emater/Ascar-RS) safra de 2011; ${ }^{2}$ José Augusto Maiorano e Jaime Duarte Filho (CATI-SP) safra de 2007/2008, ${ }^{3}$ Rafael Pio (UFLA/DAG), Emerson D. Gonçalves (Epamig/Maria da Fé), Luís Antunes (Embrapa Clima Temperado) ; ${ }^{4}$ João de Ribeiro Reis Júnior (Emater/Ascar-PR) safra de 2011/2012; ${ }^{5}$ Nelson Pires Feldberg (Epagri) ${ }^{6}$ Maria Elizabete Oliveira Abaurre (Incaper CRDR-Centro Serrano).

TABELA 2- Características fenotípicas e agronômicas das principais cultivares de amoreira-preta cultivadas no Brasil.

\begin{tabular}{|c|c|c|c|c|c|c|c|}
\hline Cultivares & $\begin{array}{c}\text { Hábito } \\
\text { de } \\
\text { crescimento* }\end{array}$ & $\begin{array}{c}\text { Presença } \\
\text { de } \\
\text { espinho* }\end{array}$ & $\begin{array}{c}\text { Massa } \\
\text { de Fruto } \\
(\mathrm{g})^{*}\end{array}$ & $\begin{array}{c}\text { SS } \\
\left({ }^{\circ} \text { Brix }\right)^{*}\end{array}$ & $\begin{array}{c}\text { Horas } \\
\text { de frio* }\end{array}$ & Finalidade & $\begin{array}{c}\text { Produtividade } \\
\qquad\left(\mathbf{t ~ h a}^{-1}\right)^{* *}\end{array}$ \\
\hline Caingangue & Ereta & Sim & $5-6$ & $9-11$ & 200 & in natura & 3,8 \\
\hline Ébano & Prostrada & Não & $4-6$ & - & - & indústria & 1,4 \\
\hline Guarani & Ereta & Sim & - & $8-10$ & - & in natura & 15,1 \\
\hline Negrita & Ereta & Sim & $5-6$ & - & - & - & - \\
\hline Tupy & Ereta & Sim & $8-10$ & $8-9$ & $200-300$ & in natura & $10,6-16,3$ \\
\hline Xavante & Ereta & Não & 6 & 8 & $200-300$ & indústria & $1,3-12,7$ \\
\hline Arapaho & Ereta & Não & $3-4$ & $7-8$ & $400-500$ & in natura & 5,5 \\
\hline Brazos & Semiereta & Sim & 8 & $8-8,5$ & - & indústria & 18,6 \\
\hline Cherokee & Ereta & Sim & $5-8$ & $8-9$ & - & in natura & 3,0 \\
\hline Comanche & Ereta & Sim & $4-7$ & - & - & in natura & 9,4 \\
\hline Choctaw & Ereta & - & 5 & $8,2-9,6$ & - & in natura & 11,4 \\
\hline
\end{tabular}

* Raseira e Franzon (2012).

** Pio et al. (2012) e dados experimentais não publicados da Embrapa Clima Temperado. Produtividade média em uma densidade de plantio de $6.667(0,5 \times 3,0)$ plantas $h^{-1}$.

TABELA 3- Período de floração e colheita das principais cultivares de amoreira-preta cultivadas no Brasil.

\begin{tabular}{|c|c|c|c|c|c|c|c|c|c|c|c|c|}
\hline Cultivares & Jan. & Fev. & Mar. & Abr. & Maio & Jun. & Jul. & Ago. & Set. & Out. & Nov. & Dez. \\
\hline \multicolumn{13}{|l|}{ Caingangue } \\
\hline \multicolumn{13}{|l|}{ Ébano } \\
\hline \multicolumn{13}{|l|}{ Guarani } \\
\hline \multicolumn{13}{|l|}{ Negrita } \\
\hline \multicolumn{13}{|l|}{ Tupy } \\
\hline \multicolumn{13}{|l|}{ Xavante } \\
\hline \multicolumn{13}{|l|}{ Arapaho } \\
\hline \multicolumn{13}{|l|}{ Brazos } \\
\hline \multicolumn{13}{|l|}{ Cherokee } \\
\hline \multicolumn{13}{|l|}{ Comanche } \\
\hline \multicolumn{13}{|l|}{ Choctaw } \\
\hline & & Flora & & & & lheita & & & & & & \\
\hline
\end{tabular}




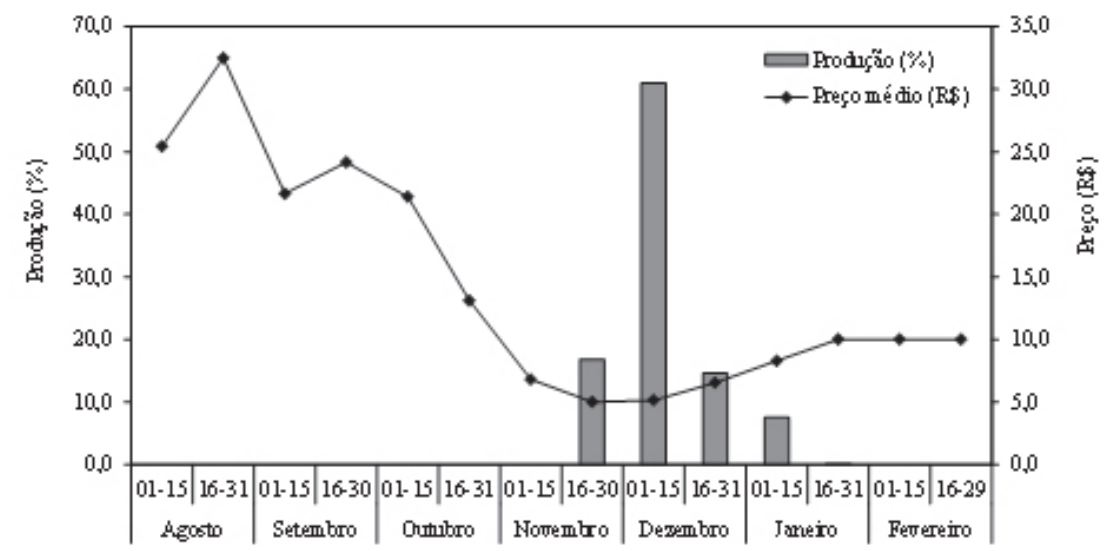

FIGURA 1- Relação entre a distribuição percentual da produção (cultivares Tupy e Xavante) e o preço pago pelo consumidor na CEASA-RS (http://www.ceasars.com.br/), safras de 2011/2012 e 2012/2013.

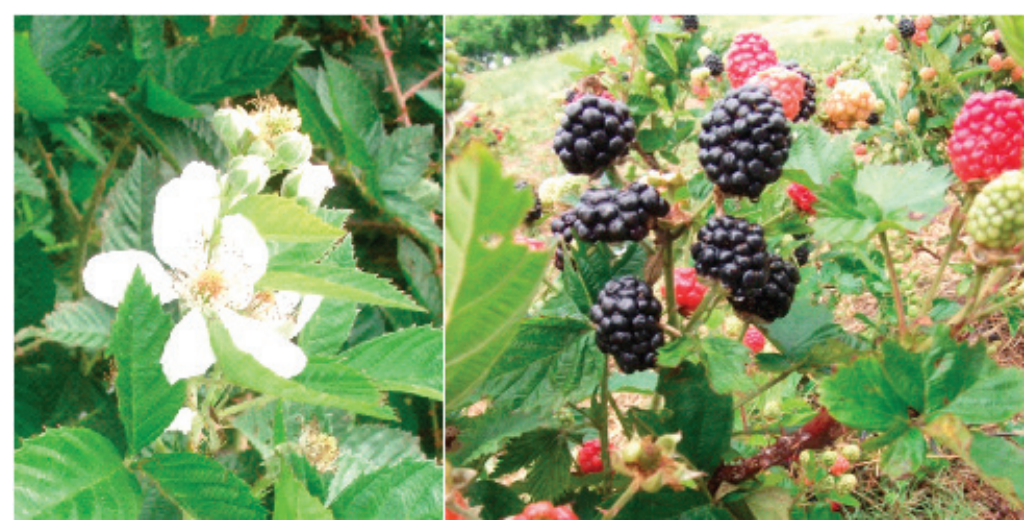

FIGURA 2- Amoreira-preta cultivar Tupy, floração e frutificação na região de Pelotas-RS.
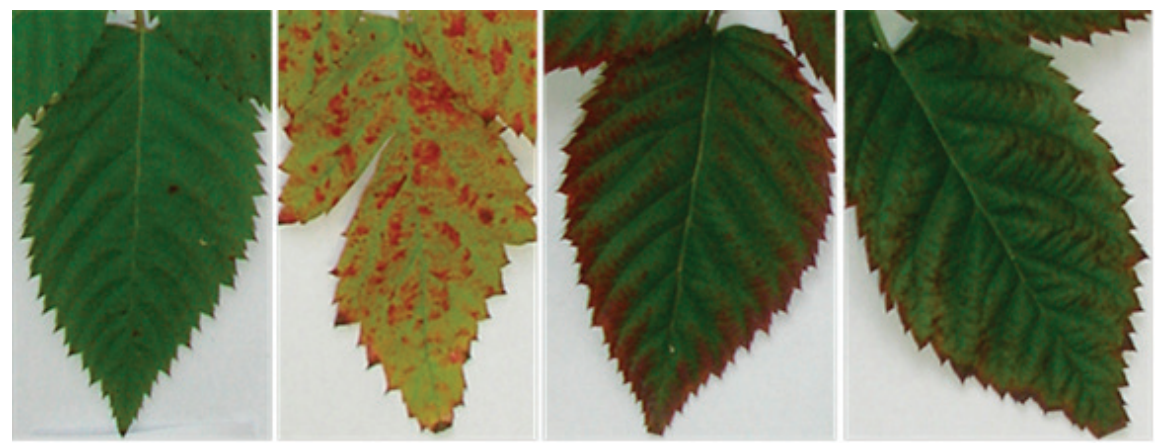

FIGURA 3-Sintomas de deficiência de moderada (A) e severa (B) de nitrogênio; de fósforo (C), e de potássio (D), em folhas de amoreira-preta. 


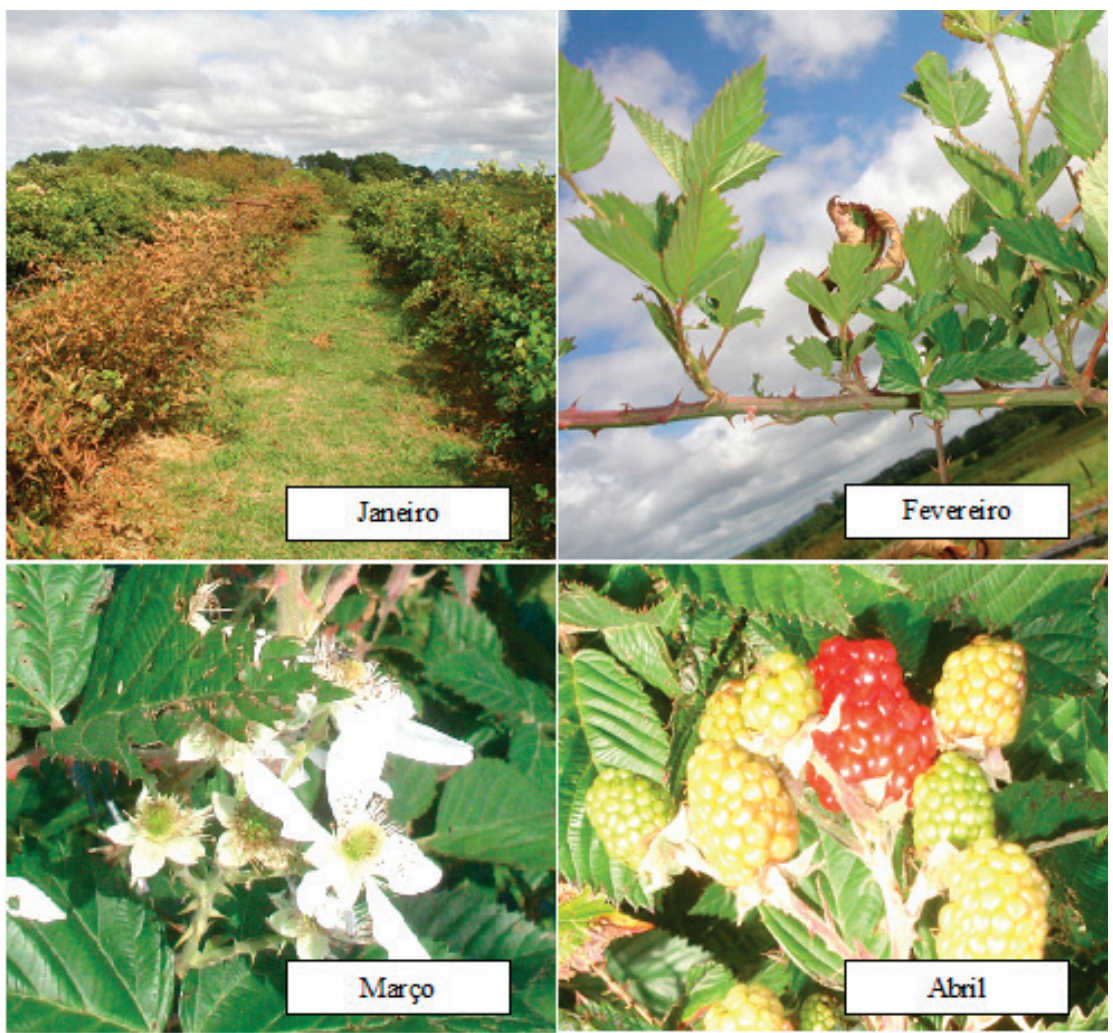

FIGURA 4- Estádios fenológicos (fevereiro, março e abril) após a aplicação de desfolhante (janeiro) em experimentos para a produção fora de época de amora-preta, realizados em 2013 na Embrapa Clima Temperado em Pelotas-RS.

\section{REFERÊNCIAS}

ANTUNES, L.E.C.; TREVISAN, R.; GONÇALVES, E. D.; FRANZON, R. C. Produção extemporânea de amora preta. Revista Brasileira de Fruticultura, Jaboticabal, v.28, n.3, p.430-434, 2006a.

ANTUNES, L. E. C.; GONÇALVES, E. D.; TREVISAN, R. Alterações de compostos fenólicos e pectina em pós-colheita de frutos de amora-preta. Revista Brasileira de Agrociência, Pelotas, v. 12, n.1, p. 57-61, 2006b.

ANTUNES, L. E. C. Amora-preta: nova opção de cultivo no Brasil. Ciência Rural, Santa Maria, v. 32, n. 1, p. 151-158, 2002.

ANTUNES, L. E. C.; DUARTE FILHO, J.; SOUZA, C. M. Conservação pós-colheita de frutos de amoreira-preta. Pesquisa Agropecuária Brasileira, Brasília, v.38, n.3, p.413-419, 2003.
ANTUNES, L. E. C.; GONÇALVES, E. D.; TREVISAN, R. Alterações da atividade da poligalactutonase e pectinametilesterase em amorapreta (Rubus spp) durante o armazenamento. Revista Brasileira de Agrociência, Pelotas, v. 12, n.1, p. 63-66, 2006c.

ANTUNES, L. E. C.; GONÇALVES, E. D.; TREVISAN, R. Fenologia e produção de cultivares de amoreira-preta em sistema agroecológico. Ciência Rural, Santa Maria, v.40, n.9, p.1929-1933, 2010.

CALDERÓN, Z. G.; RODRÍGUEZ, A. J. Respuesta de la frambuesa roja (Rubus idaeus L.) 'Heritage' a aspersiones de ácido giberélico en invernadero. Revista Fitotecnia Mexicana, Chapingo, v.15, p.85-94, 1992.

CAMPAGNOLO, M. A.; PIO, R. Produção da amoreira-preta 'Tupy' sob diferentes épocas de poda. Ciência Rural, Santa Maria, v.42, n.2, 2012. 
CAMPOY, J.A.; RUIZ, D.; EGEA, J. Dormancy in temperate fruit trees in a global warming context: A review. Scientia Horticulturae, Amsterdam, v.130, p.357-372, 2011.

CIA, P.; URBANO, I.; BRON; VALENTINI, S. R. T.; PIO, R.; CHAGAS, E. A. Atmosfera modificada e refrigeração para conservação pós-colheita da amora-preta. Bioscience Journal, Uberlândia, v.23, n.3, p.11-16, 2007.

CQFS - Comissão de Química e Fertilidade do Solo - RS/SC. Manual de adubação e calagem para os estados do Rio Grade Sul e Santa Catarina. 10.ed. Porto Alegre: SBCS-NRS, 2004. 400p.

DICKERSON, G. W. Blackberry production in New Mexico. Las Cruces: New Mexico State University, 2000. 8p. (Guide H-325)

FACHINELLO, J. C.; PASA, M. da S.; SCHMTIZ, J. D.; BETEMPS D. L. Situação e perspectivas da fruticultura de clima temperado no Brasil. Revista Brasileira de Fruticultura, Jaboticabal, p.109-120, 2011. Volume Especial.

FERNANDEZ, G.; BALLINGTON, J. R. Growing Blackberries in North Carolina. Raleigh: North Carolina State University, 1999. 9p.

FREIRE, C. J. da S. Nutrição e adubação. In: ANTUNES, L. E. C.; RASEIRA, M. do C.B. (Ed.). Cultivo da amoreira-preta. Pelotas: Embrapa Clima Temperado, 2007. p.45-54. (Sistemas de Produção, 12)

GALINDO-REYES, M. A.; GONZÁLEZHERNÁNDEZ, V.; MURATALLA-LÚA, A.A.; SOTO-HERNÁNDEZ, M. R.; LIVERA-MUÑOZ, M. Producción forzada en zarzamora 'comanche' mediante reguladores de crecimiento. Revista Chapingo Serie Horticultura, Chapingo, v.10, n.2, p.205-209, 2004.

GALLETTA C. J.; HEMILRICK, D. C. Small fruit crop management. New Jersey: Prentice Hall, 1990. p.157-213.

GAZDA, A.; KOCHMANSKA-BEDNARZ, A. Comparison of the size structure of the blackberry (Rubus hirtus Waldst. \& Kitt. agg.) from the populations growing on the soils developed on different geological substrates. Sylwan, Krakow, v.154, n.5, p.347-355, 2010.
GEORGE, A. P.; NISSEN, R. J.; BAKER, J. A. Effects of hydrogen cyanamide in manipulating budburst and advancing fruit maturity of table grapes in south-eastern Queensland. Australian Journal of Experimental Agriculture, Collingwood, v.28, p.533-538, 1998.

GONÇA LVES, E. D.; PIMENT EL, R. M. de A.; LIMA, L. C. de O.; CASTRICINI, A.; ZAMBON, C. R.; ANTUN ES, L. E. C.; TREVISAN , R. Manutenção da qualidade pós-colheita das pequenas frutas. Informe Agropecuário, Belo Horizonte, v.33, n 268, p.89-95, 2012.

GONÇALVES, E.D., ZAMBON, C.R.; SILVA, D.F.; SILVA , L.F.O.; PIO, R.; ALVARENGA, A.A.; CAPRONI, C. M. Implantação, manejo e pós-colheita da amoreira preta.Belo Horizonte: EPAMIG, 2011. 5p. (Circular Técnica, 140)

GRANDALL, P. C. Bramble production: the management and marketing of raspberries and blackberries. Binghamton: Haworth Press, 1995. 172p.

HANSON, E.; WEIHE, M. V.; SCHILDER, A. C.; CHANON, A. M.; SCHEERENS, J. C. High tunnel and open field production of floricane- and primocanefruiting raspberry cultivars. HortTechnology, Alexandria, v.21, n.4, p.412-418, 2011.

HART, J.; STRIK, B.; REMPEL, H. Caneberries: nutrient management guide. Corvallis: Oregon State University, 2006. 8p.

HIRSCHI, G. E.; FACCO, E. M. P.; RODRIGUES, D. B.; VIZZOTTO, M.; EMANUELLI, T. Caracterização físico-química de variedades de amora-preta da região sul do Brasil. Ciência Rural, Santa Maria, v.42, n.5, p.942-947, 2012.

ILHA, L. H. Produção de amora-preta e framboesa em regiões de clima temperado. Informe Agropecuário, Belo Horizonte, v.33, n 268, p.58-68, 2012.

JACQUES, A. C.; ZAMBIAZI, R. C. Fitoquímicos em amora-preta (Rubus spp) Semina: Ciências Agrárias, Londrina, v. 32, n. 1, p. 245-260, 2011.

JOO, M.; LEWANDOWSKI, N.; AURAS, R.; HARTE, J.; ALMENAR, E. Comparative shelf life study of blackberry fruit in bio-based and petroleumbased containers under retail storage conditions. Food Chemistry, Zürich, v.126, p.1734-1740, 2011. 
PAGOT, E.; SCHNEIDER, E. P.; NACHTIGAL, J. C.; CAMARGO D. A. Cultivo da Amora-preta. Bento Gonçalves: Embrapa Uva e Vinho, 2007. 11p. (Circular Técnica, 75)

PAPP J.; KOBZOS-PAPAI I.; NAGY, J. Effect of Nitrogen application on yield, leaf nutrient status and fruit chemical composition of raspberry and redcurrant varieties. Acta Agronomica Academiae Scientiarum Hungaricae, Budapest, v.33, p.337343, 1984.

PEREIRA, I. S. Adubação de pré plantio no crescimento, produção e qualidade da amoreirapreta (Rubus sp.). 2008. 148 f. Dissertação (Mestrado) - Faculdade de Agronomia Eliseu Maciel, Universidade Federal de Pelotas, Pelotas, 2008.

PEREIRA, I. S.; ANTUNES, L. E. C.; FACHINELLO, J. C.; MESSIAS, R. S.; SILVEIRA; C. A. P.; VIGNOLO, G. Avaliações da subtração dos elementos $\mathrm{N}$, P e K sobre o crescimento vegetativo da amoreira-preta. Pelotas: Embrapa Clima Temperado, 2012. 8p. (Comunicado Técnico, 276)

PIO, R.; ALVARENGA, A. A.; MOURA, P. H. A.; CURI, P. N. Produção de amora-preta e framboesa em regiões de clima quente. Informe Agropecuário, Belo Horizonte, v.33, n.268, p.46-55, 2012.

RASEIRA, M. do C. B.; FRANZON, R. C. Melhoramento genético e cultivares de amora-preta e mirtilo. Informe Agropecuário, Belo Horizonte, v.33, n.268, p.11-20, 2012.

RETAMALES, J. B. World temperate fruit production: characteristics and challenges. Revista Brasileira de Fruticultura, Jaboticabal, p.121-130, 2011. Numero Especial.

SCHAKER, P. D. C.; ANTONIOLLI, L. R. Aspectos econômicos e tecnológicos em pós-colheita de amoras-pretas (Rubus spp). Revista Brasileira de Agrociência, Pelotas, v.15, n.1-4, p.11-15, 2009.

SEGANTINI, D. M.; LEONEL, S.; RIPARDO, A. K. da S.; AURICCHIO, MARCELO G. R. Uso de reguladores de crescimento para a superação da dormência e sua influência na brotação, no florescimento e na produção da amoreira-preta. Revista Brasileira de Fruticultura, Jaboticabal, v.33, p. 275-280, 2011. Número Especial.
STRIK, B. C. A review of nitrogen nutrition of Rubus. Acta Horticulturae, The Hague, v.777, p.403-410, 2008.

STRIK, B. C., CLARK, J. R., FINN, C. E., BAÑADOs, M. P. Worldwide blackberry production. HortTechnology, Alexandria, v.17, n.2, p.205-213, 2007.

STRIK, B. C.; FINN, C. E. Blackberry production systems - a worldwide perspective. Acta Horticulturae, The Hague, v.946, p.341-348, 2012.

THERON, K. I.; GERBER, H. J.; WILLEM, J. S. Effect of hydrogen cyanamide, mineral oil and thidiazuron in combination with tip pruning on bud break, shoot growth and yield in 'Bourjasotte Noire', 'Col de Damme Noire' and 'Noire de Caromb' figs. Scientia Horticulturae, Amsterdam, v.128, p.239248, 2011.

THOMPSON, E.; STRIK, B. C.; FINN, C. E.; ZHAO, Y.; CLARK, J. R. High tunnel vs. open field: management of primocane-fruiting blackberry using pruning and tipping to increase yield and extend the fruiting season. HortScience, Alexandria, v.44, p.1581-1587, 2009.

VIZZOTTO, M.; RASEIRA, M. do C. B.; PEREIRA, M. C.; FETTER, M. da R. Teor de compostos fenólicos e atividade antioxidante em diferentes genótipos de amoreira-preta (Rubus sp.). Revista Brasileira de Fruticultura, Jaboticabal, v.34, n.3, p.853-858, 2012.

VOLK, G. M.; OLMSTEAD, J. W.; FINN, C. E.; JANICK, J. The ASHS Outstanding Fruit Cultivar Award: A 25-year Retrospective. Hortscience, Alexandria, v. 48, n. 1, p. 4-12, 2013.

WU, R.; FREI, B.; KENNEDY, J. A.; ZHAO, $\mathrm{Y}$. Effects of refrigerated storage and processing technologies on the bioactive compounds and antioxidant capacities of 'Marion' and 'Evergreen' blackberries. Food Science and Technology, London, v.43, p.1253-1264, 2010. 